\title{
RISK ASSESSMENT OF MINED AREAS USING FUZZY INFERENCE
}

\author{
Salem S. M. Khalifa ${ }^{1}$, Kamarudin Saadan $^{2}$ and Norita Md. Norwawi ${ }^{3}$ \\ ${ }^{1,2,3}$ Universiti Sains Islam Malaysia, Faculty of Science \& Technology, Bandar BaruNilai, \\ 71800 Nilai, Negeri Sembilan, Malaysia
}

\begin{abstract}
During the World War I, II over fifty countries in the world today have been inherited a legacy of antipersonnel landmines and unexploded ordnance (UXO) which represents a major threat to lives, and hinders reconstruction and development efforts. Landmines have specific properties that make it harder to detect .Therefore; these properties lead landmine detectors to become more complex. Many examples can be found to address the increasing complexity of Landmines detection; unfortunately, these new techniques are high of cost and need experts to deal with it. Many developing countries face financial difficulties to get advanced technologies for detection landmines such as Robotic systems, this due to their high cost, use and maintenance difficulties which makes them unaffordable to these countries. The safety of operators, transportability, ease of maintenance and operation are the most factors that must take into consideration to improve the applicability and effectiveness of landmines tracking systems.The aim of the study is to proposed architecture of Intelligent Wireless Landmines Tracking System (IWLTS) with new decision model based on fuzzy logic.To find an affordable, light and easy to use alternative which meet users' needs to protect and warn them from the risk of landmines during practice their lives, we suggested the design and development of Fuzzy Inference Model for IWLTS using Smart Phone.Fuzzy model require three step which are definitions of Linguistic Variable and fuzzy sets, determine fuzzy rules and the process of Fuzzy Inference.Designed Fuzzy Inference Model gives both: Landmine risk value in percentage and alert to avoid that risk.
\end{abstract}

KEYWORDS: Fuzzy logic, Membership Function, Fuzzy Rule, Fuzzy Inference System, Matlab, Landmines, Risk Assessment

\section{Introduction}

One of the biggest problems that faced many countries and affects civilians and soldiers throughout the world in recent years is landmines. There are a lot of countries around the world suffer from the problem of mines, unfortunately there is no official report to detect the number of mines planted in the world, but it is estimated by the United Nations to be at least 100 million land mines may to be currently active in the world [1].Millions of people who live in slums where there are few other sources of income depend on the careers related to animal agriculture. Thus, these people are threatened by many of dangers during their life. Children often work in agriculture and grazing sheep to help their families under difficult conditions which creates serious problems and may put them at risk of landmines. Even in places where wars happened long ago, people can still be exposed to threats from landmines. 
The idea behind this paper is to merge artificial intelligence techniques with smart phones for assess risks associated with landmines, furthermore , to find a low cost alternative to protect and warn people from the risk of landmines during practicing their life.

Probability models have become the fundamental basis in risk quantification and assessment. However, they may not be able to describe some risks in a meaningful and practical way, because they were based upon classical set theory. There are another models might do a better job in understanding and assessing certain risks such as artificial neural and Bayesian networks ,fuzzy logic, and hidden Markov and decision tree models [2].

In the following section (2), we presented the fuzzy logic and the philosophical ideas behind it. Section (3) presented Related Work on the usage of fuzzy logic in Mine clearance while Section (4) presented an overview of Background of the study. Section (5), the proposed of fuzzy inference model of IWLTS system was presented. Section (6) the fuzzy inference model of IWLTS system has been tested .Finally, Section (7) presented the conclusions and the features expected from the model.

\section{FUZZY LOGIC}

Fuzzy logic can be defined is a form of many-valued logic which deals with reasoning that is approximate rather than fixed and exact. Fuzzy logic variables may have a truth value that ranges in degree between 0 and 1, compared to traditional binary sets (where variables may take on true or false values).

\subsection{Fundamental Concepts of Fuzzy Logic}

In 1965, Lotfi A. Zadeh described a Fuzzy logic as a form or system of logic based on set theory of fuzzy sets [3] [4] [5] [6], who later developed many of the methods of fuzzy logic based on this simple theory, thus establishing the foundation of a comprehensive and mathematically sound logic of imprecisely or ambiguously defined sets.

\subsection{Fuzzy sets and membership functions}

Fuzzy set has been defined as a set with fuzzy boundaries whose elements have a degree of membership [7]. It has an infinite range of truth values which can be anywhere in the range from 0 to 1 , normally it is called the degree of membership.

In classical set theory, the membership function $f_{A}(x)$ : can only take the values 0 and 1 :

$f_{A}(x): x \rightarrow 1,0$,

Where

$f_{A}(x)=\left\{\begin{array}{r}1, \text { if } x \ni A \\ 0, \text { if } x \nexists A\end{array}\right.$.

While in the fuzzy theory, fuzzy set $A$ of universe $X$ is defined by function $\mu A(x)$ called the membership function of set $A$.

$\mu A(x) x \rightarrow[0,1]$. 
$\mu A(x)=1$, if $x$ is an element of the set $A$.

$\mu A(x)=0$, if $x$ is not an element of the set $A$.

Where $A$ is a fuzzy set and $x$ is an element of fuzzy set $A$.

\section{RELATED WORK.}

The techniques of risk analysis are most important tools that used to support people for decision making in emergency operations. Several risk analysis techniques currently are used to evaluate and estimate risk, which can be classified into categories as shown in table 1.

Table 1 Fuzzy risk analysis applications

\begin{tabular}{|c|c|c|}
\hline $\begin{array}{l}\text { Research } \\
\text { area }\end{array}$ & Description & $\begin{array}{l}\text { Reference } \\
\quad \mathrm{s}\end{array}$ \\
\hline $\begin{array}{c}\text { E- } \\
\text { commerce }\end{array}$ & $\begin{array}{l}\text { This paper describes how to use a fuzzy decision support system } \\
\text { (FDSS) to assess a risk in e-commerce (EC). }\end{array}$ & {$[8]$} \\
\hline $\begin{array}{c}\text { Project } \\
\text { Management }\end{array}$ & $\begin{array}{l}\text { This paper presents a new approach called a fuzzy adaptive } \\
\text { decision making model for selection of balanced risk among the } \\
\text { contracting parties using the fuzzy logic. }\end{array}$ & [9] \\
\hline \multirow{8}{*}{$\begin{array}{c}\text { Risk } \\
\text { management }\end{array}$} & $\begin{array}{l}\text { These papers describe a new approach for designing and } \\
\text { developing a novel risk assessment model considering human } \\
\text { factor using fuzzy logic where the Lab VIEW program have been } \\
\text { used to develop the risk assessment interface. }\end{array}$ & {$[10],[11]$} \\
\hline & $\begin{array}{l}\text { This paper presents the new developed fuzzy QRAM model, to } \\
\text { reduce occupational safety risks which was designed based on } \\
\text { chemistry and engineering, biomechanical data and laws of } \\
\text { physics }\end{array}$ & {$[12]$} \\
\hline & $\begin{array}{l}\text { proposes the application of Mamdani type fuzzy inference in } \\
\text { modelling the risk of service interruption as one of the criteria } \\
\text { used in distribution network planning }\end{array}$ & [13] \\
\hline & $\begin{array}{l}\text { Presents the lightning risk assessment based on fuzzy mathematics } \\
\text { by three aspects of hazard, exposure and vulnerability of hazard } \\
\text { bearing body. }\end{array}$ & [14] \\
\hline & $\begin{array}{l}\text { In this paper, the fuzzy logic is used to propose a new approach } \\
\text { which aims in risk classification of coronary artery heart disease } \\
\text { in female diabetic patients. }\end{array}$ & {$[15]$} \\
\hline & $\begin{array}{l}\text { Describes the risk classification of diabetic nephropathy using } \\
\text { fuzzy logic. }\end{array}$ & {$[16]$} \\
\hline & $\begin{array}{l}\text { In this paper, fuzzy inference systems (FISs) have been used to } \\
\text { proposes a new method for the probabilistic risk assessment of } \\
\text { rotor angle instability in power systems }\end{array}$ & [17] \\
\hline & $\begin{array}{l}\text { This paper presents a monitoring system that is used to assess the } \\
\text { current risk level during sport activity based on personal } \\
\text { parameters. }\end{array}$ & {$[18]$} \\
\hline
\end{tabular}

The latest developments in Artificial Intelligence Technologies as well as the widespread usage of sensors have led to the recent prevalence of new techniques for mines detection. There are 
several hybrids technologies that have been designed and developed for detecting mines [19]. One of these technologies is Fuzzy logic which has been used by many researchers in detecting mines. Progress in application of the fuzzy logic technique led to improve in devices in several fields of science including detecting mines. Because it provides a rich set of mathematical tools, it can help to detect risks of landmines as early as possible in an uncertain environment.

Alshbatat, A. I. N. [20] presented a new approach for detection of land Mines based on fuzzy logic (Autonomous Robot).He has designed and developed intelligent controller which could be used to enable and control the robot to detect mines based on fuzzy rules as shown in Figure 1.The system consists of four subsystems which aims to generate a weighting factor that represents the degree of robot orientation where are then attached to the engine (defuzzifier) for the purpose of creating the fuzzy values to steer the robot to the desired location.

Gader et al [21], [22] proposed a variety of algorithms (a gradient-based method for landmine detection) to recognize the hyperbola-like curves in a GPR image from a landmine. These algorithms used a fuzzy set approach to aggregate information from a variety of information sources generated from novel ground penetrating radar. The first approach gives an answer with regard to the various detection errors of the system and returns high precision result only if the MCA (multi channel amplifier) energy calibration error is limited, while the second approach overrides this limit.

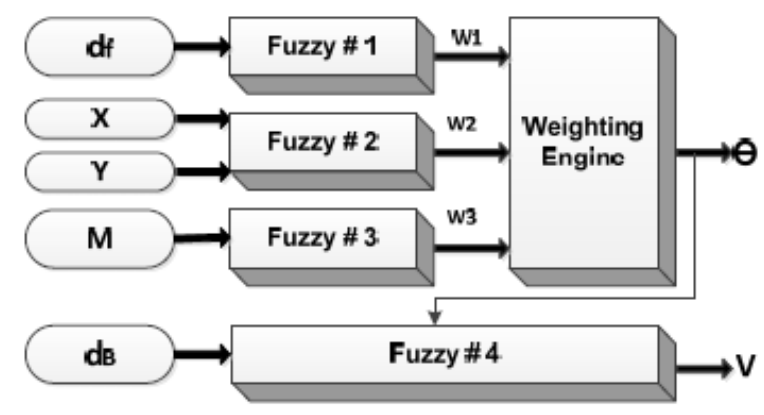

Figure 1 Structure of the proposed fuzzy controller [9]

\section{BACKGROUND OF THE STUDY}

During recent years, the application of Fuzzy Set Theory concept has been demonstrated in various fields worldwide [23] including assessment the risks associated with landmines. It is applied in detection and monitoring landmines using robot and radar.

The need to plan for ways to reduce harm and to develop new technical for tracking landmines with flexible mobile platforms is an urgent. In order to reduce injuries resulting from landmines, it is necessary for us to detect potential risks in advance. One of the main reasons behind this development is to reduce of the risk mine. In our study, we use Fuzzy logic with mobile phone to assess risks associated with landmines in case get closer the areas affected by landmines. 


\section{DesCription OF THE Proposed FuZzy IWLTS InFERENCE MODEL}

It is generally known that usage fuzzy inference models are very important in applications, especially if information is uncertain and imprecise. They have been successfully applied in fields such as robotics, medicine, control, modeling, and so forth. In this section, a detailed description of the IWLTS Fuzzy system Model is presented.

Mamdani-type [24], Sugeno-type [25], [26] and Tsukamoto-type [27] are three types of fuzzy inference systems in wide use; the most commonly used fuzzy inference technique is the socalled Mamdani method. It was proposed in 1975 by EbrahimMamdani [28]. All these methods are similar except the way outputs are determined. In light of all of this, we decided to use first the Mamdani Fuzzy model and then use the Sugeno Fuzzy model to make sure the result in our model based fuzzy logic.

The Fuzzy IWLTS Inference Model involves two (2) inputs which were carefully selected from the expert and useful articles from the Internet. In this study the Fuzzy IWLTS Inference Model is a fuzzy inference system that uses a fuzzy partition of input from smart phone represented in two linguistic variables (signal strength and position of user), while the output of this model is the assessment of the risk levels (Risk).

To develop fuzzy model, we should follow the following steps:

\subsection{Definitions of Linguistic Variable and fuzzy sets}

Definition 1: Basic fuzzy linguistic variable

A fuzzy linguistic variable is a 4-tuple $(X, T, M, A)$,

Where:

$X$ is the name of fuzzy linguistic variable.

In the fuzzy theory, fuzzy set $A$ of universe $X$ is defined by function $\mu A(x)$ called the membership function of set $A$.

$\mu A(x): X \rightarrow\left[\begin{array}{ll}0 & 1\end{array}\right]$

$\mu A(x)=\left\{\begin{array}{c}1, \text { if } x \text { is totaly in } A \\ 0, \text { if } x \text { is not in } A \\ \in(0,1), \text { if } x \text { is partialy in } A\end{array}\right.$

(5)

$T$ term set of linguistic values (fuzzy variables).

$M$ is the mapping.

$A$ is the universe of discourse.

\section{Definition 2:}

Extend fuzzy linguistic variable Extend fuzzy linguistic is 5-tuple $O_{F}=(c a, C F, R, F, A),(6)$ 
Where:

$c a$ is a concept on the abstract level (Signal-Quality, Position, Risk).

$X$ is the corresponding element of $c a$ in definition.

$C F$ is the set of fuzzy concepts which describes all values of $c a$.

$T$ is the corresponding element of $C F$ in definition 1 (Poor, Average, Excellent).

$R$ is the fuzzy relation between concepts in $C F$.

$F$ is the set of membership functions at $A$.

$A$ has same interpretations as defined in definition 1.

To define membership functions for converting the crisp set into fuzzy set, we have used Triangular and trapezoidal membership functions in our proposed model. MATLAB is a highlevel language and interactive environment with a collection of functions called Matlab toolbox that enable user to analyze data, develop algorithms, and create models and applications [29] [30]. In our study, all rules and fuzzy set have been developed using Matlab with the Fuzzy Logic toolbox.

For our problem there are two variables (inputs) determine the degree of danger and one output (Risk) of landmines. The first input is wireless network (Signal Strength) that coming from the cell towers, second input is (position ) of user that coming from GPS .These input variables are usually measured by mobile phone's sensors

Signal Strength: Checking a state of GSM signal is very important for IWLTS system. Landing for GSM Signal level would be caused in stopping the system and posing a real threat for user's life. Therefore, IWES system monitors regularly the dynamics of the strength level change of GSM Signal to avoid these risks. Usually the Signal strength ranges from $-113 \mathrm{dBm}$ (poor) to $50 \mathrm{dBm}$ (Excellent).

The variable of Signal-strength can be defined as:

$\boldsymbol{O}_{F 1}($ Signal-Strength $)=(c a=$ Signal- Strength, $C F=\{$ Poor, Average, Excellent $\}, R=\{$ Poor $\leq$ Average $\leq$ Excellent $\left.\}, \quad F=\left\{\mathrm{F}_{\text {Poor }}(\mathrm{x}), \mathrm{F}_{\text {Average }}(\mathrm{x}), \mathrm{F}_{\text {Excellent }}(\mathrm{x})\right\}, A=[-50,-113]\right)$.

Next table 2 presents the fuzzy sets of the Signal-Strength variable, while figure (2) shows the membership functions.

Table 2: Fuzzy set of input variable for Signal-Strength

\begin{tabular}{|c|c|}
\hline Linguistic Variable & Interval (dBm) \\
\hline Poor & $\{-113,-113,-99,-92\}$ \\
\hline Average & $\{-106,-85,-64\}$ \\
\hline Excellent & $\{-78,-64,-50,-50\}$ \\
\hline
\end{tabular}




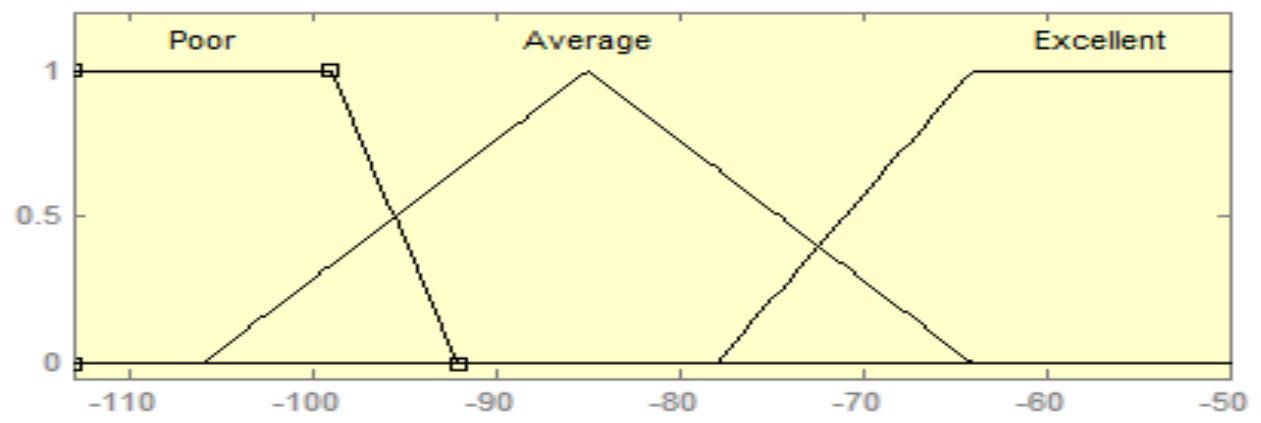

Figure 2: Membership functions for Input Variable Signal-Strength

Location: This variable is obtained by using the Global Positioning System (GPS) and positioning technologies that utilized in cellular networks using a GSM cellular network. The location will be used to calculate the distance between the user and the areas-landmines affected.

The variable of Location can be defined as:

$O_{F 2}($ Location $)=(c a=$ Location, $C F=\{$ Inside, Beside, Far-away $\}, R=\{$ Inside $\leq$ near-side $\leq$ Faraway $\left.\}, F=\left\{\mathrm{F}_{\text {Inside }}(\mathrm{x}), \mathrm{F}_{\text {Beside }}(\mathrm{x}), \mathrm{F}_{\text {Far-away }}(\mathrm{x})\right\}, A=[0,200]\right)$.

The fuzzy sets of the Location variable are given in Table 3, while the membership functions are shown in Figure 3.

Table 3 Fuzzy set of input variable for Location.

\begin{tabular}{|c|c|}
\hline Linguistic Variable & Interval (Meter) \\
\hline Inside & $\{0,0,25,45\}$ \\
\hline Beside & $\{30,50,70\}$ \\
\hline Far-away & $\{55,75,100,100\}$ \\
\hline
\end{tabular}

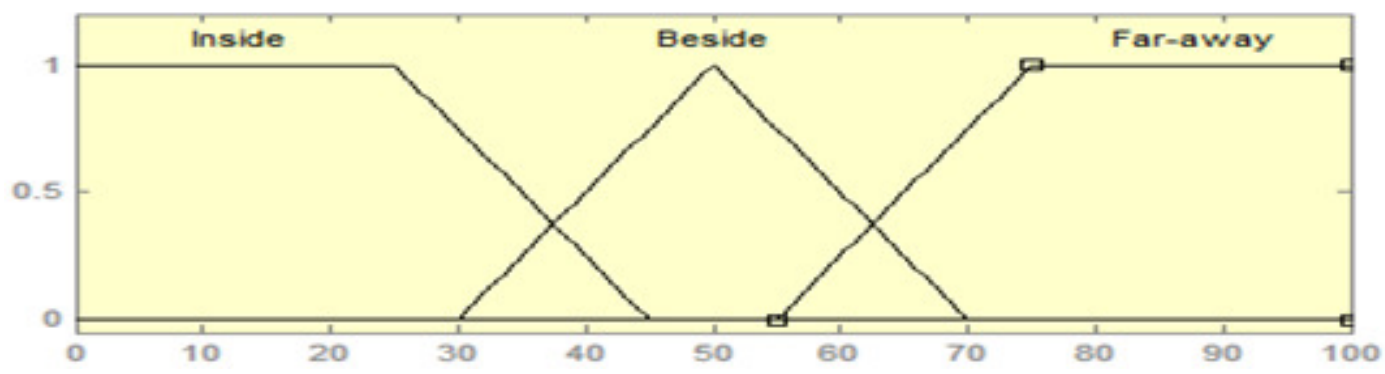

Figure 3 Membership functions for Input Variable Location

Risk: Risk is considered as the output of the fuzzy model. The ranges of the risk of landmines can be determined by expert judgments (Deminers).In other words, we can ask the expert to give numbers between 0 and 1 per cent that represent the safe distance between the user and the areaslandmines affected. 
The variable of Risk can be defined as:

$O_{F 3}($ Risk $)=(c a=$ Risk, $C F=\{$ Very-Low, Low, Moderate, High, Very-High $\}, R=\{$ Very-Low $\leq$ Low $\leq$ Moderate $\leq$ High $\leq$ Very-High $\}, F=\left\{\mathrm{F}_{\text {Very-Low }}(\mathrm{x}), \mathrm{F}_{\text {Low }}(\mathrm{x}), \mathrm{F}_{\text {Moderate }}(\mathrm{x}), \mathrm{F}_{\text {High }}(\mathrm{x}), \mathrm{F}_{\text {Very-High }}\right.$ (x) $\}, A=[0,1])$.

The fuzzy sets of the Risk variable are given in Table 4, while the membership functions are shown in Figure 4.

Table 4: Fuzzy set of out variable for Risk

\begin{tabular}{|c|c|}
\hline Linguistic Variable & Interval \\
\hline Very-Low & $\{0,0,0.15,0.25\}$ \\
\hline Low & $\{0.102,0.252,0.402\}$ \\
\hline Moderate & $\{0.25,0.5,0.75\}$ \\
\hline High & $\{0.6,0.75,0.9\}$ \\
\hline Very-High & $\{0.75,0.85,1,1\}$ \\
\hline
\end{tabular}

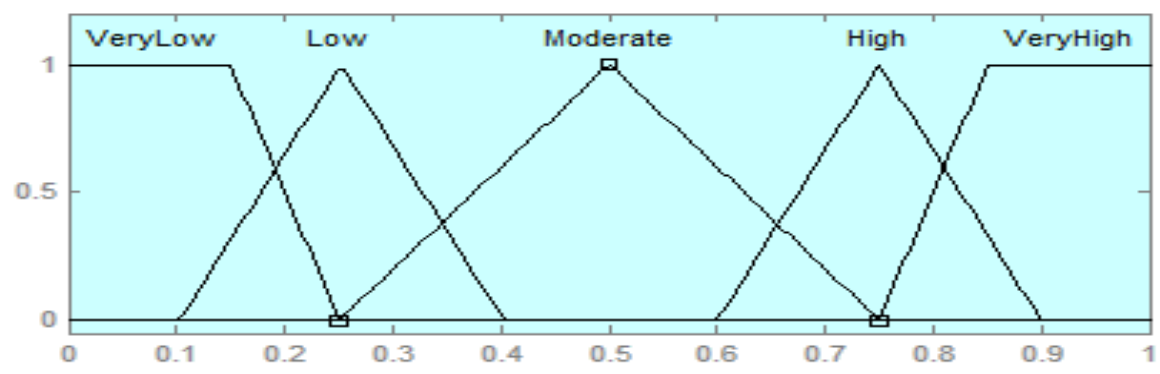

Figure 4 Membership functions for output Variable Risk

\subsection{Determine fuzzy rules}

Fuzzy rule and fuzzy reasoning are the most important modeling tool based on fuzzy set theory where are considered the backbone of fuzzy inference systems [31]. We built the following fuzzy rules that constitute the basis of the IWLTS Fuzzy System according to Mamdani models.The following Figure presents fuzzy rules that constitute the basis of the IWLTS System.

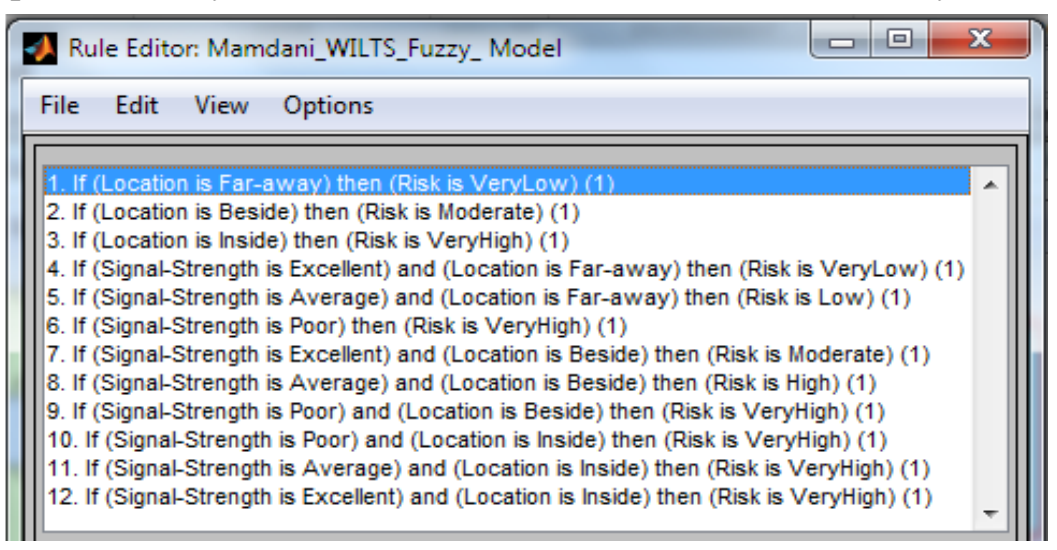

Figure 5: Fuzzy Rule of the IWLTS Fuzzy system Model 


\subsection{The process of Fuzzy Inference}

The basic structure of The Fuzzy IWLTS Inference Model consists of three conceptual components as shown in figure 6: (1) Fuzzy input, output variables and their fuzzy values; (2) a rule base, which contains a selection of fuzzy rules; (3) fuzzy inference methods (Fuzzification, Defuzzification).In our model, all these steps have been performed using Matlab Toolbox.

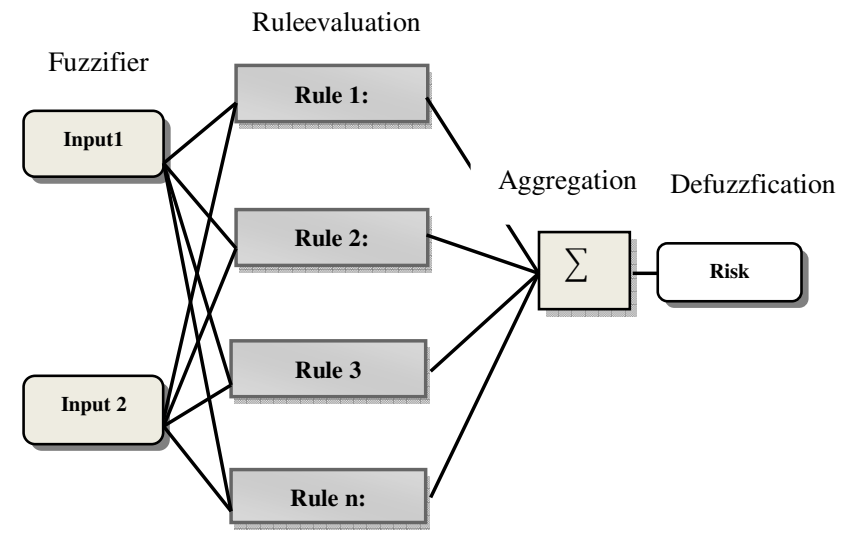

Figure 6 Fuzzy Inference for the IWLTS Fuzzy system Model

\section{a) Fuzzification.}

Fuzzification is the first step in the fuzzy inference process where the standard (ordinary inputs) are transformed into fuzzy inputs, so that each ordinary (crisp) input has its own group of membership functions or sets to which they are transformed.

We, supposed that we have two inputs, the first input (Signal strength $=-95 \mathrm{dBm}$ ) and the second input $($ Location $=50 \mathrm{M}$ ). In this case, we rated the Signal strength has an -95 , which, given graphical definition of poor, corresponds to $\mu=0.4$ for the Average membership function as in Figure 7.

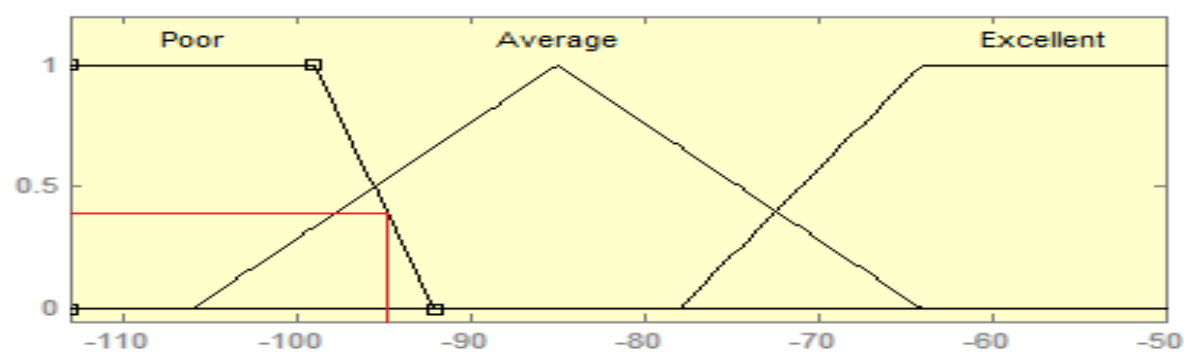

Figure 7:Fuzzifying of input variable "Signal strength"

In the same way, we rated the Location has 50, which, given graphical definition of beside, corresponds to $\mu=1$ for the beside membership function as in Figure 8 . 


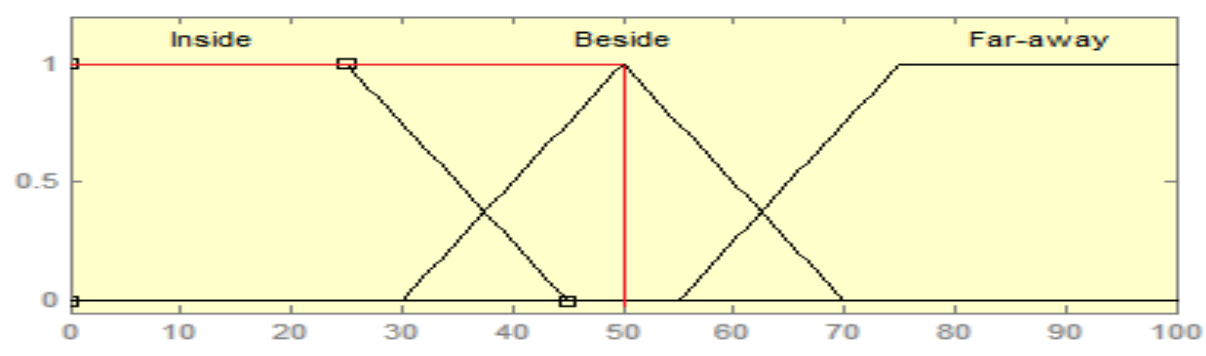

Figure 8: Fuzzifying of input variable "Location"

\section{b) Rule evaluation.}

The aim of the next step is to take the fuzzified inputs and puts them to the previous of the fuzzy rules. Figure 9 depicts rule evaluation and the results obtained.

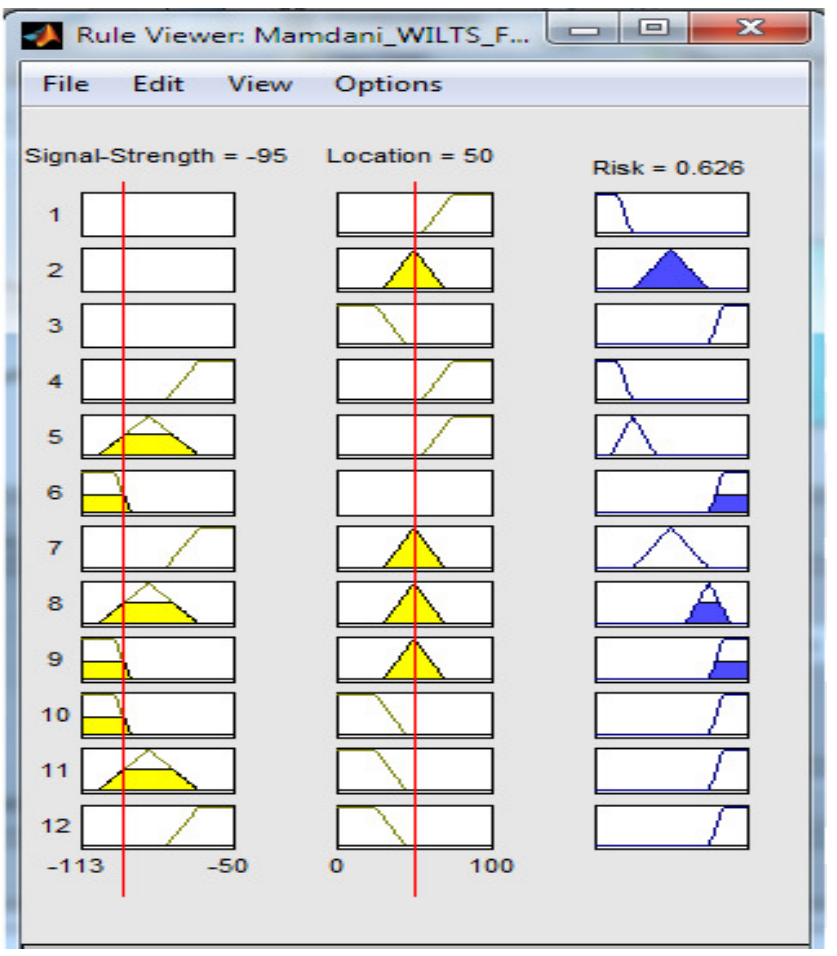

Figure 9: Rule evaluation following Mamdani fuzzy model.

\section{c) Aggregation of the outputs.}

The Aggregation process aims to take the membership functions of all rule consequents previously scaled and grouped together into a single fuzzy set. Thus, the input of the aggregation process is the list of clipped or scaled consequent membership functions, and the output is one fuzzy set for each output variable [32]. 
Figure 10 presents the output of each rule is aggregated into a single fuzzy set for the overall fuzzy output.

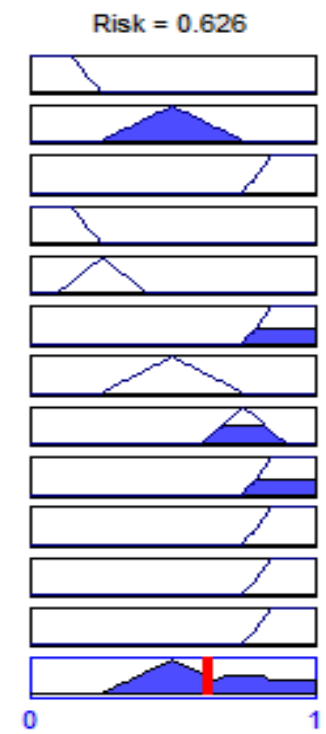

Figure 10: Results aggregation.

\section{d) Defuzzification}

The last step in fuzzy-molecular inference model is Defuzzification process that is used to resolve a crisp value from the results of the inference process. The most common method used for Defuzzification in the formulas below is considered as following:

$C O G=\frac{\sum_{x=a}^{b} \mu A(x) x}{\sum_{x=a}^{b} \mu A(x)}$

In our model, we have now obtained the fuzzy results and have to defuzzify them to get a crisp output. The interpretation of the output may be that the Risk is Moderate with a $60 \%$ as in Figure 11.

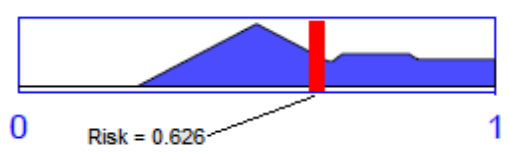

Figure 11: Defuzzifying the solution variable's fuzzy set

\section{MODEL EXECUTION AND VALIDATION}

We can also check the results by Real Time Evaluation. The IWLTS Fuzzy system Model have been tested 13 time .Table 5 shows the result of test. The testing is done using a MATLAB program. We have rebuilt our model using Sugeno (or Takagi-Sugeno-Kang) method, and then we have made a comparison between previous methods. 
International Journal of Artificial Intelligence \& Applications (IJAIA) Vol. 6, No. 2, March 2015

Table 5: Results of testing with 12 rules

\begin{tabular}{|c|c|c|c|c|}
\hline \multirow{2}{*}{ Seq } & Input (X1) & Input (X2) & \multicolumn{2}{|c|}{ Output (Z) } \\
\cline { 2 - 5 } & $\begin{array}{c}\text { Signal Strength } \\
(\mathbf{d B m})\end{array}$ & $\begin{array}{c}\text { Position } \\
(\text { Meter) }\end{array}$ & $\begin{array}{c}\text { Mamdani } \\
\text { Method }\end{array}$ & $\begin{array}{c}\text { Sugeno } \\
\text { Method }\end{array}$ \\
\cline { 4 - 5 } & -109.8 & 50 & $0.68 \%$ & $0.667 \%$ \\
\hline 2 & -104.6 & 35.91 & $0.748 \%$ & $0.752 \%$ \\
\hline 3 & -75.72 & 65 & $0.362 \%$ & $0.199 \%$ \\
\hline 4 & -63.58 & 65 & $0.3 \%$ & $0.134 \%$ \\
\hline 5 & -91.33 & 64.09 & $0.391 \%$ & $0.241 \%$ \\
\hline 6 & -57.8 & 25 & $0.9 \%$ & $0.8 \%$ \\
\hline 7 & -53.76 & 50.45 & $0.5 \%$ & $0.4 \%$ \\
\hline 8 & -93.64 & 82.27 & $0.275 \%$ & $0.167 \%$ \\
\hline 9 & -101.2 & 91.36 & $0.486 \%$ & $0.379 \%$ \\
\hline 10 & -71.1 & 68.64 & $0.227 \%$ & $0.0734 \%$ \\
\hline 11 & -91.9 & 93.18 & $0.157 \%$ & $0.0803 \%$ \\
\hline 12 & -76.88 & 69.55 & $0.19 \%$ & $0.803 \%$ \\
\hline 13 & -113 & 0 & $0.9 \%$ & $0.8 \%$ \\
\hline
\end{tabular}

We have used Surface Viewer to view the dependency of one of the outputs on any one or two of the inputs to generate and plot an output surface map for the IWLTS Fuzzy Model. Figure 12 show the output surface viewer of the IWLTS Fuzzy Model according to Mamdani.

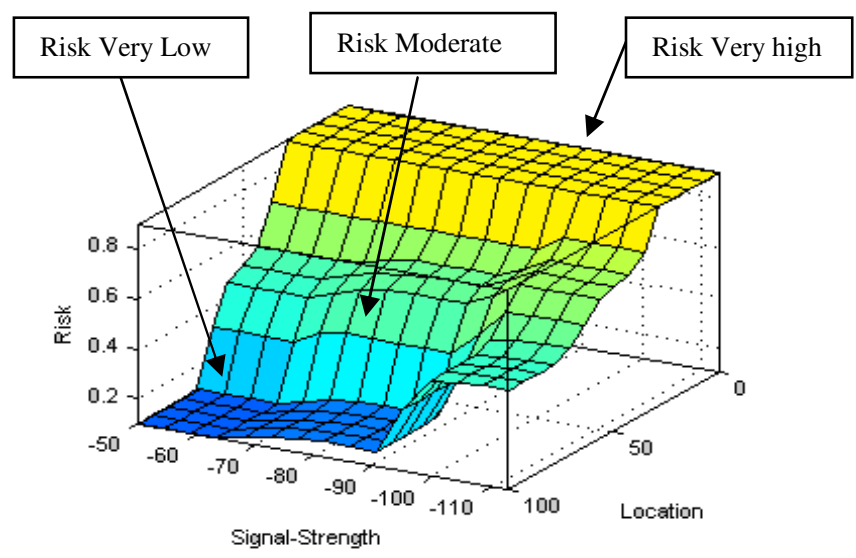

Figure 12 Three-dimensional plots for 12 rules according to Mamdani method 
International Journal of Artificial Intelligence \& Applications (IJAIA) Vol. 6, No. 2, March 2015

\section{LIMITATIONS OF THIS STUDY}

Although the Fuzzy IWLTS Inference Model comes out with many advantages, it still has some limitations. The limitations of the Fuzzy IWLTS Inference Model are summarized below:

- There are a lot of challenges in front of the Telecommunication Development information and communication in developing countries where these countries suffer from a lack of infrastructure, particularly the information and communication technologies. Concentrated terrestrial infrastructure in these countries is mostly in urban centers with limited coverage for rural and remote areas. . Based on that, the Fuzzy IWLTS Inference Model relies entirely on the signal strength and location of the user, thus any failure to receive the signal leads to stop the system.

- The Fuzzy IWLTS Inference Model only provides the level of risk based on two inputs (Signal Strength and Position of user). Although, the results (Table 5) that have been gotten are not exhaustive, it is suitable enough for the purpose of this study.

- Due to the lack of equipment for mining surveying and the lack of available information about the areas affected by landmines, the model has been tested using a local server with test data only. Thus, this model needs to be tested using real data.

\section{CONCLUSION AND FUTURE WORK.}

Mine detection process is a complex phenomenon which requires application of logical decision making and optimization framework. Imperfect information and uncertainty are two very important system attributes which add complexity to planning and development process. This paper proposed the application of Mamdani type fuzzy inference in modelling the risk of landmines called IWLTS Fuzzy System Model. This model has been built according to the most popular model (Mamdani Fuzzy models). The IWLTS Fuzzy System Model provides a viable solution in form of maps and alerts to user through his mobile phone in case of exposure to landmines risk. It has been developed through several phases according to Mamdani method. The first phase where Linguistic Variables, fuzzy sets and membership function have been defined. The second phase is determining fuzzy rules according to the investigation and analysis on the features of landmines and the Consult the experts. The third phase is fuzzy Inference which is the core of the IWLTS Fuzzy System Model that consists of Fuzzification, Rule evaluation, Aggregation of the outputs and Defuzzification..

The suggested Fuzzy Inference Model can be re-applied in many fields such as: estimating the risks associated areas contaminated by nuclear radiation, endemic areas of communicable diseases and areas of natural disasters such as floods and landslides

In the future, it is planned to integrate between the GPS, GIS, DSS and Smart phone into one coherent environment called (Hybrid Framework Intelligent Wireless Landmines Tracking System), which will be used to implement prototype based on fuzzy principles. 
International Journal of Artificial Intelligence \& Applications (IJAIA) Vol. 6, No. 2, March 2015

\section{REFERENCES}

[1] Landmines (1998) Mine Action News United Nations, 4th quarter, vol. 3.2.

[2] Shang, K., \&Hossen, Z. (2012). Applying Fuzzy Logic to Risk Assessment and Decision-Making .CAS/CIA/SOA.

[3] Zadeh, L. A. (1965). Fuzzy sets. Information and control, 8(3), 338-353.

[4] Netto, E. (1901). Lehrbuch der Combinatorik (Vol. 7). BG Teubner.

[5] Nilsson, N. J. (1971). Problem-solving methods in. Artificial Intelligence.

[6] Rodjito, P. (2006). Position tracking and motion prediction using Fuzzy Logic.Honors Theses, 520.

[7] Negnevitsky, M. (2005). Artificial intelligence: a guide to intelligent systems. Pearson Education.

[8] Ngai, E. W., \&Wat, F. K. T. (2005). Fuzzy decision support system for risk analysis in e-commerce development. Decision support systems, 40(2), 235-255.

[9] Khazaeni, G., Khanzadi, M., \&Afshar, A. (2012). Fuzzy adaptive decision making model for selection balanced risk allocation. International Journal of Project Management, 30(4), 511-522.

[10] Li, P. C., Chen, G. H., Dai, L. C., \& Li, Z. (2010). Fuzzy logic-based approach for identifying the risk importance of human error. Safety science, 48(7), 902-913.

[11] Aras, F., Karakaş, E., \&Biçen, Y. (2014). Fuzzy logic-based user interface design for risk assessment considering human factor: A case study for high-voltage cell. Safety science, 70, 387-396.

[12] Pinto, A. (2014). QRAM a qualitative occupational safety risk assessment model for the construction industry that incorporate uncertainties by the use of fuzzy sets. Safety Science, 63, 57-76.

[13] Saric, M. (2014, November). Fuzzy approach for evaluating risk of service interruption used as criteria in electricity distribution network planning. In Neural Network Applications in Electrical Engineering (NEUREL), 2014 12th Symposium on (pp. 79-84). IEEE.

[14] Yu, S., \&Ren, Y. (2014, October). Research on the lightning risk assessment method for Chongqing based on fuzzy mathematics. In Lightning Protection (ICLP), 2014 International Conference o (pp. 1054-1057). IEEE.

[15] Narasimhan, B., \&Malathi, A. (2014, March). A Fuzzy Logic System with Attribute Ranking Technique for Risk-Level Classification of CAHD in Female Diabetic Patients. In Intelligent Computing Applications (ICICA), 2014 International Conference on (pp. 179-183). IEEE.

[16]Narasimhan, B., \&Malathi, A. (2014, March). Fuzzy logic system for risk-level classification of diabetic nephropathy. In Green Computing Communication and Electrical Engineering (ICGCCEE), 2014 International Conference on (pp. 1-4). IEEE.

[17] Preece, R., \&Milanovic, J. V. (2014 ) Probabilistic Risk Assessment of Rotor Angle Instability Using Fuzzy Inference Systems. IEEE TRANSACTIONS ON POWER SYSTEMS

[18] Toth-Laufer, E. (2014, May). Fuzzy logic-based sport activity risk assessment framework optimization. In Applied Computational Intelligence and Informatics (SACI), 2014 IEEE 9th International Symposium on (pp. 129-134). IEEE.

[19] Bruschini, C., \&Gros, B. (1997, September). A survey of current sensor technology research for the detection of landmines. In Proc. International Workshop on Sustainable Humanitarian Demining (Vol. 6, pp. 18-27).

[20] Alshbatat, A. I. N. (2013). Behavior-Based Approach for the Detection of Land Mines Utilizing off the Shelf Low Cost Autonomous Robot. IAES International Journal of Robotics and Automation (IJRA), 2(3), 83-92.

[21] Gader, P. D., Keller, J. M., \& Nelson, B. N. (2001). Recognition technology for the detection of buried land mines. Fuzzy Systems, IEEE Transactions on,9(1), 31-43. 
International Journal of Artificial Intelligence \& Applications (IJAIA) Vol. 6, No. 2, March 2015

[22] Gader, P. D., Nelson, B. N., Frigui, H., Vaillette, G., \& Keller, J. M. (2000). Fuzzy logic detection of landmines with ground penetrating radar. Signal Processing, 80(6), 1069-1084.

[23] Balanică, V., Dumitrache, I., Caramihai, M., Rae, W., \&Herbst, C. (2011). Evaluation of breast cancer risk by using fuzzy logic. UPB Sci. Bull., Series C,73(1).

[24] Mamdani, E. H., \&Assilian, S. (1975). An experiment in linguistic synthesis with a fuzzy logic controller. International journal of man-machine studies, 7(1), 1-13.

[25] Sugeno, M., \& Kang, G. T. (1988). Structure identification of fuzzy model.Fuzzy sets and systems, 28(1), 15-33.

[26] Takagi, T., \&Sugeno, M. (1985). Fuzzy identification of systems and its applications to modeling and control. Systems, Man and Cybernetics, IEEE Transactions on, (1), 116-132.

[27] Tsukamoto, Y. (1979). An approach to fuzzy reasoning method. Advances in fuzzy set theory and applications, 137, 149.

[28] Yager, R. R., \&Filev, D. P. (1994). Generation of fuzzy rules by mountain clustering. Journal of Intelligent and Fuzzy Systems, 2(3), 209-219.

[29] MathWorks (2013)Retrieved on (13/3/2014) fromhttp://www.mathworks.com/

[30] (2014) The MathWorkswebsite. [Online]. Available: http://www.mathworks.com/products/matlab/

[31] Jang, J. S. R., \& Sun, C. T. (1996). Neuro-fuzzy and soft computing: a computational approach to learning and machine intelligence. Prentice-Hall, Inc.

[32] Negnevitsky, M. (2005). Artificial intelligence: a guide to intelligent systems. Pearson Education. 